\title{
Preliminary experience with a transcranial magnetic resonance-guided focused ultrasound surgery system integrated with a 1.5-T MRI unit in a series of patients with essential tremor and Parkinson's disease
}

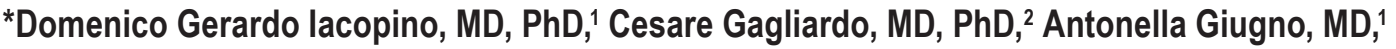 \\ Giuseppe Roberto Giammalva, MD, ${ }^{1}$ Alessandro Napoli, MD, PhD, ${ }^{3}$ Rosario Maugeri, MD, PhD, ${ }^{1}$ \\ Francesca Graziano, MD, ${ }^{1}$ Francesca Valentino, MD, PhD, ${ }^{4}$ Giuseppe Cosentino, MD, PhD, ${ }^{4}$ \\ Marco D’Amelio, MD, PhD, ${ }^{4}$ Tommaso Vincenzo Bartolotta, MD, PhD, ${ }^{2}$ Carlo Catalano, MD, PhD, ${ }^{3}$ \\ Brigida Fierro, MD, PhD, ${ }^{4}$ Massimo Midiri, MD, PhD, ${ }^{2}$ and Roberto Lagalla, MD, $\mathrm{PhD}^{2}$
}

${ }^{1}$ Unit of Neurosurgery, Department of Experimental Biomedicine and Clinical Neuroscience, University of Palermo; ${ }^{2}$ Section of Radiological Sciences, Department of Biopathology and Medical Biotechnologies, University of Palermo; ${ }^{3}$ Radiology Section, Department of Radiological, Oncological and Anatomopathological Sciences, "Sapienza" University of Rome; and 4Unit of Neurology, Department of Experimental Biomedicine and Clinical Neuroscience, University of Palermo, Italy

\begin{abstract}
OBJECTIVE Transcranial magnetic resonance-guided focused ultrasound surgery (tcMRgFUS) is one of the emerging noninvasive technologies for the treatment of neurological disorders such as essential tremor (ET), idiopathic asymmetrical tremor-dominant Parkinson's disease (PD), and neuropathic pain. In this clinical series the authors present the preliminary results achieved with the world's first tcMRgFUS system integrated with a 1.5-T MRI unit.

METHODS The authors describe the results of tcMRgFUS in a sample of patients with ET and with PD who underwent the procedure during the period from January 2015 to September 2017. A monolateral ventralis intermedius nucleus (VIM) thalamic ablation was performed in both ET and PD patients. In all the tcMRgFUS treatments, a 1.5-T MRI scanner was used for both planning and monitoring the procedure.

RESULTS During the study period, a total of 26 patients underwent tcMRgFUS thalamic ablation for different movement disorders. Among these patients, 18 were diagnosed with ET and 4 were affected by PD. All patients with PD were treated using tcMRgFUS thalamic ablation and all completed the procedure. Among the 18 patients with ET, 13 successfully underwent tcMRgFUS, 4 aborted the procedure during ultrasound delivery, and 1 did not undergo the tcMRgFUS procedure after stereotactic frame placement. Two patients with ET were not included in the results because of the short follow-up duration at the time of this study. A monolateral VIM thalamic ablation in both ET and PD patients was performed. All the enrolled patients were evaluated before the treatment and 2 days after, with a clinical control of the treatment effectiveness using the graphic items of the Fahn-Tolosa-Marin tremor rating scale. A global reevaluation was performed 3 months (17/22 patients) and 6 months (11/22 patients) after the treatment; the reevaluation consisted of clinical questionnaires, neurological tests, and video recordings of the tests. All the ET and PD treated patients who completed the procedure showed an immediate amelioration of tremor severity, with no intra- or posttreatment severe permanent side effects.
\end{abstract}

CONCLUSIONS Although this study reports on a small number of patients with a short follow-up duration, the tcMRgFUS procedure using a 1.5-T MRI unit resulted in a safe and effective treatment option for motor symptoms in

\footnotetext{
ABBREVIATIONS BBB = blood-brain barrier; ET = essential tremor; FRFSE = fast recalled FSE; FSE = fast spin echo; FSPGR = fast spoiled gradient echo; FTM = FahnTolosa-Marin; HI-FU = high-intensity focused ultrasound; MS = multiple sclerosis; PD = Parkinson's disease; QUEST = Quality of Life in Essential Tremor; SWAN = susceptibility-weighted angiography; tcMRgFUS = transcranial magnetic resonance-guided focused ultrasound surgery; UPDRS = Unified Parkinson's Disease Rating Scale; VIM = ventralis intermedius nucleus.
}

SUBMITTED September 29, 2017. ACCEPTED November 27, 2017

INCLUDE WHEN CITING DOI: 10.3171/2017.11.FOCUS17614.

* Drs. lacopino and Gagliardo contributed equally to this work. 
patients with ET and PD. To the best of the authors' knowledge, this is the first clinical series in which thalamotomy was performed using tcMRgFUS integrated with a 1.5-T magnet.

https://thejns.org/doi/abs/10.3171/2017.11.FOCUS17614

KEY WORDS magnetic resonance-guided focused ultrasound surgery; MRgFUS; high-intensity focused ultrasound ablation; brain; stereotactic technique; Parkinson's disease; essential tremor; MRI; interventional

I $\mathrm{N}$ the recent past, surgical stereotactic lesioning of the thalamus and basal ganglia has been used for the treatment of different cerebral functional disorders. In this setting, magnetic resonance-guided focused ultrasound surgery (MRgFUS) has emerged as a noninvasive thermal ablation method, which uses high-intensity focused ultrasound (HI-FU) energy and MRI for anatomical imaging and real-time thermal mapping. ${ }^{48}$ Thanks to this novel technology, today it is possible to obtain a rigorous focal point within the planned target and across the intact skull for the treatment of neurological disorders. , $^{6,13,36,43}$

The HI-FU adopted in MRgFUS generates its effects on target tissues through several mechanisms: direct heating, cavitation, and shear stress. ${ }^{52}$ Since its development, the most recent technologies have allowed the use of HIFU in neurosurgical practice. ${ }^{1,21,28,30,31,52}$ MRI guidance is used for both the planning and the thermal monitoring of the targeted area, thanks to water proton resonance frequency-shift thermometry. ${ }^{30,35}$

At the beginning, MRgFUS was used to treat both benign and malignant neoplasms. ${ }^{24,27,49}$ Currently, this procedure is being used for new clinical and experimental scenarios. ${ }^{3,14,15,35}$ In functional neurosurgery, transcranial MRgFUS (tcMRgFUS) is definitely emerging as a noninvasive, nonprosthetic, guided, and repeatable technique for treating mostly idiopathic tremor-dominant Parkinson's disease (PD), essential tremor (ET), and neuropathic pain. $1,11,36,51$

ET and PD are neurological disorders with a high prevalence. The history of their pathological progression leads to drug resistance and to the decline of quality of life..$^{8,16}$, ${ }^{20,26}$ In this clinical series we aim to present the results obtained by treating tremor in patients suffering from ET and PD with the world's first tcMRgFUS system integrated with a 1.5-T MRI unit.

\section{Methods}

\section{Patients and Study Criteria}

From January 2015 to September 2017 at the University Hospital "Paolo Giaccone" of Palermo, Italy, 26 patients underwent tcMRgFUS thalamic ablation for different functional and movement disorders: 20 patients suffered from ET, 4 patients suffered from PD, 1 patient suffered from neuropathic pain, and 1 patient suffered from intentional tremor secondary to multiple sclerosis (MS). Among these 26 patients, only 23 were enrolled in this study: 18 with ET, 4 with PD, and the 1 patient with MS (Table 1). The patient with MS was not treated because of a sudden laryngospasm while she was lying on the MRI machine, before the sonications were performed. The 4 patients with PD (4 men, mean age $68 \pm 4.74$ years) were all treated by tcMRgFUS thalamic ablation and completed the procedure. Among the 18 patients with ET (13 men, 5 women, mean age $65 \pm 13.02$ years), 13 successfully underwent tcMRgFUS (10 men, 3 women, mean age 65.22 \pm 11.87 years), 4 aborted the procedure during ultrasound delivery, and 1 did not undergo tcMRgFUS after stereotactic frame placement. Two patients with ET were not considered for treatment because of a short follow-up duration at the time of manuscript submission. The patients who completed the procedure were treated by monolateral tcMRgFUS ventralis intermedius nucleus (VIM) thalamic ablation both in cases of ET and in cases of PD.

Eligibility criteria were age between 18 and 80 years, patient ability to give informed consent and undergo clinical evaluations, the possibility of performing CT and MRI, and a proper skull density ratio. In both ET and PD patients, tremor had to be confirmed by a movement disorder-skilled neurologist, be resistant to a stable dose of medications, and cause substantial disability in daily life. The interruption of pharmacological therapy before the treatment, because of its inefficiency, was not considered an exclusion criterion. Every patient who did not meet such eligibility criteria, suffered from psychiatric illness, presented a risk of bleeding, had neurological and cardiovascular comorbidities, had dermatological illness on the scalp, or had a standard contraindication to CT/MRI was excluded from the treatment. Demographic data are shown in Table 1.

\section{Outcome Evaluation}

All enrolled patients were evaluated before the treatment (baseline). The follow-up evaluations were performed 2 days and then 3 (17/22 patients) and 6 months (11/22 patients) after the treatment. These evaluations consisted of clinical questionnaires, neurological tests, and video recordings of the tests.

Tremor severity was evaluated by the neurosurgeons using the Fahn-Tolosa-Marin (FTM) tremor rating scale in the patients with ET, and the third section of the Unified Parkinson's Disease Rating Scale (UPDRS) in the 4 patients with PD.

For the purpose of this study, only the scores obtained from patients who completed the tcMRgFUS procedure were considered and analyzed. For each patient with ET, the global FTM score (range 0-144) was assessed before treatment and at the 3- and 6-month follow-up evaluations; the second section of the FTM scale (graphic ability, range $0-16$ ) for the contralateral hand was also evaluated on the 2nd day after the treatment to assess the immediate improvement in graphic abilities.

All the patients with ET enrolled in this series were 
TABLE 1. Demographic data of enrolled patients

\begin{tabular}{|c|c|c|c|c|c|c|c|}
\hline $\begin{array}{l}\text { Case } \\
\text { No. }\end{array}$ & $\begin{array}{l}\text { Age (yrs), } \\
\text { Sex }\end{array}$ & Disorder & $\begin{array}{c}\text { Disease } \\
\text { Duration (yrs) }\end{array}$ & tcMRgFUS & Therapy at Treatment & $\begin{array}{c}\text { Treated } \\
\text { Hand }\end{array}$ & $\begin{array}{l}\text { FU } \\
\text { (mos) }\end{array}$ \\
\hline 1 & $45, M$ & ET & 45 & Completed & Gabapentin, clonazepam, delorazepam, domperidone & Rt & 6 \\
\hline 2 & $70, \mathrm{M}$ & ET & 4 & Completed & Pregabalin, duloxetine & Rt & 6 \\
\hline 3 & $75, \mathrm{~F}$ & ET & 15 & Completed & Propranolol & Rt & 6 \\
\hline 4 & $77, \mathrm{M}$ & ET & 25 & Completed & Suspended before treatment due to inefficacy & Rt & 6 \\
\hline 5 & $35, \mathrm{M}$ & ET & 10 & Completed & Mirtazapine, delorazepam & $\mathrm{Lt}$ & 6 \\
\hline 6 & $75, \mathrm{~F}$ & ET & 70 & Completed & Clonazepam, pregabalin, duloxetine, trazodone & Rt & 6 \\
\hline 7 & $67, \mathrm{M}$ & ET & 3 & Completed & Primidone & Rt & 6 \\
\hline 8 & $75, \mathrm{M}$ & ET & 20 & Completed & Propranolol & Rt & 6 \\
\hline 9 & $53, \mathrm{M}$ & ET & 5 & Completed & Propranolol, clonazepam & Rt & 3 \\
\hline 10 & $71, \mathrm{M}$ & ET & 63 & Completed & Bromazepam, primidone & Rt & 6 \\
\hline 11 & $72, \mathrm{M}$ & ET & 6 & Completed & Suspended before treatment due to inefficacy & Rt & 3 \\
\hline 12 & $55, \mathrm{M}$ & ET & 10 & Completed & Propranolol & Rt & 6 \\
\hline 13 & $75, \mathrm{~F}$ & ET & 15 & Completed & Primidone & Rt & 6 \\
\hline 14 & $70, F$ & ET & 10 & Aborted (severe HA) & Delorazepam & Rt & Aborted \\
\hline 15 & $71, \mathrm{M}$ & ET & 21 & Aborted (severe HA) & Suspended before treatment due to inefficacy & Rt & Aborted \\
\hline 16 & $50, \mathrm{M}$ & ET & 25 & Aborted (severe HA) & Primidone & $\mathrm{Rt}$ & Aborted \\
\hline 17 & $66, \mathrm{M}$ & ET & 20 & Aborted (low temp) & Propranolol, primidone & Rt & Aborted \\
\hline 18 & $72, \mathrm{~F}$ & ET & 22 & $\mathrm{NP}(\mathrm{TIA})$ & Suspended before treatment due to inefficacy & NP & NP \\
\hline 19 & $52, \mathrm{~F}$ & MS & 5 & NP (laryngospasm) & Paroxetine, baclofen & NP & NP \\
\hline 20 & $61, \mathrm{M}$ & PD & 14 & Completed & Levodopa, carbidopa, quetiapine, pregabalin & Rt & 3 \\
\hline 21 & $74, \mathrm{M}$ & PD & 30 & Completed & Melevodopa, carbidopa, pramipexole & Rt & 3 \\
\hline 22 & $67, \mathrm{M}$ & PD & 6 & Completed & Levodopa, carbidopa, oxybutynin & $\mathrm{Rt}$ & 3 \\
\hline 23 & $70, \mathrm{M}$ & PD & 6 & Completed & Levodopa, carbidopa, pramipexole, amitriptyline & Rt & 3 \\
\hline
\end{tabular}

$\mathrm{FU}=$ follow-up; $\mathrm{HA}=$ headache; $\mathrm{NP}=$ not performed; temp = temperature; $\mathrm{TIA}=$ transient ischemic attack.

The right hand was the tremor-dominant hand in all patients.

also evaluated with the Quality of Life in Essential Tremor (QUEST) questionnaire at baseline and at 3- and 6-month follow-up evaluations to assess their quality of life (range $0 \%-100 \%$, in which $100 \%$ is the greatest perceived disability and the worst quality of life).

For each patient with PD, the third section of the UPDRS was assessed before the treatment (baseline) and at 3 months. No evaluation at 6 months has been performed yet.

Patients underwent neurological assessment before and after each treatment. Moreover, after each sonication, the tremor and its amelioration were assessed by a clinical evaluation and drawing tests.

Brain screening and follow-up MRI were performed with a Signa HDxt 1.5-T unit (GE Medical Systems) using an 8-channel phased-array head coil. The MRI conventional protocol used for screenings and follow-up evaluations included 2D axial fast spin echo (FSE) T1- and T2weighted pulse sequences, sagittal T2-weighted 3D CUBE FLAIR with fat saturation, sagittal 3D T1-weighted fast spoiled gradient echo (FSPGR), and axial 3D susceptibility-weighted angiography (SWAN; 3-mm thickness). The tcMRgFUS specific planning protocol included sagittal, coronal, and axial high-resolution (2-mm-thick/no gap) T2-weighted fast recalled FSE (FRFSE). The same planning sequences were used for live MRI during the treat- ments, using a dedicated 2-channel head coil. CT brain scans were acquired using a 16-channel multidetector CT unit (BrightSpeed, GE Medical Systems) with the following parameters: tube voltage $120 \mathrm{kV}$, tube current $220 \mathrm{~mA}$, pure axial plane $\left(0^{\circ}\right.$ gantry tilting $)$, sequential acquisition, $1.25-\mathrm{mm}$ slice thickness, and bone kernel.

\section{tcMRgFUS Thalamotomy Procedure}

This tcMRgFUS system (ExAblate 4000, InSightec Ltd.) consists of a hemispheric 1024-element phased-array transducer operating at $650 \mathrm{kHz}$, similar to those used with 3.0-T MRI units?

Before the procedure, the patient's scalp was shaved and fixed with the stereotactic frame (Fig. 1A), and a sealant membrane with the embedded dedicated coil was positioned on the head of the patient (Fig. 1B). Once the frame was locked to the helmet, the helmet itself was filled with degassed circulating cooled water for an optimal coupling and to avoid any heat damage to the skin and to the skull. During the treatment, the patient and both the monitoring and the operating physicians had access to an emergency stop sonication button. Patient vital signs were constantly monitored during each procedure.

Target position was calculated on MR images by canonical stereotaxic coordinates: $75 \%$ of the intercommissural line (anterior commissure-posterior commissure 


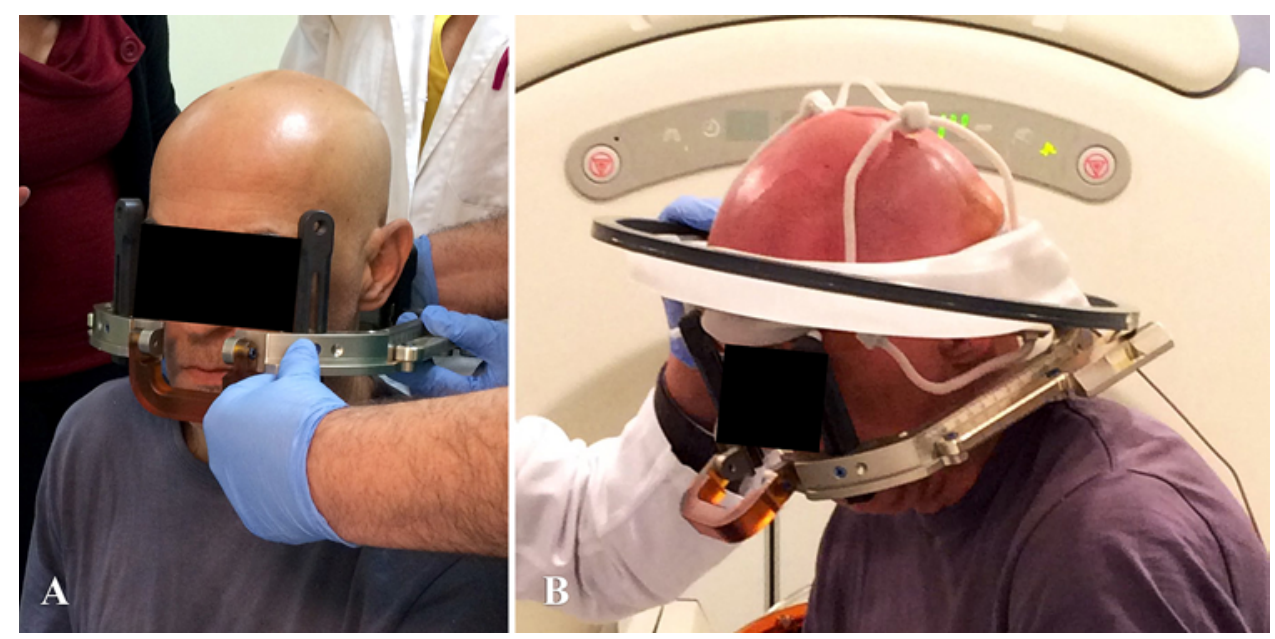

FIG. 1. Images showing patient preparation for tcMRgFUS. A: Stereotactic frame positioning. B: Patient sitting on the dedicated MRI table with the stereotactic frame fixed and the silicon sealant membrane already positioned; 1 of the 2 rings of the dedicated coil is clearly visible on the left side of the patient's head.

line), 12-14 mm laterally from the median plane, and 0-2 $\mathrm{mm}$ caudocranially from the intercommissural plane. For each patient, the treatment was planned by registering the CT and MRI images, marking as "no pass" regions any calcifications and other critical regions that could affect the HI-FU path. The number of transducer elements that had to be employed (should not be $<700$ ) and the actual head surface (should not be $<250 \mathrm{~cm}^{2}$ ) available for the energy required to be delivered were thus calculated. Fi- ducial markers were placed on live MR images to enable automatic movement detection.

Before starting the procedure, a tracking scan was run to verify and register the transducer home position, and the central MRI frequency was verified. The transducer's focal point and the MRI system alignment in all 3 axes were verified before the actual treatment by performing short (10-second) low-energy sonications ( $\leq 250 \mathrm{~W})$. The HI-FU beam power was then gradually increased to

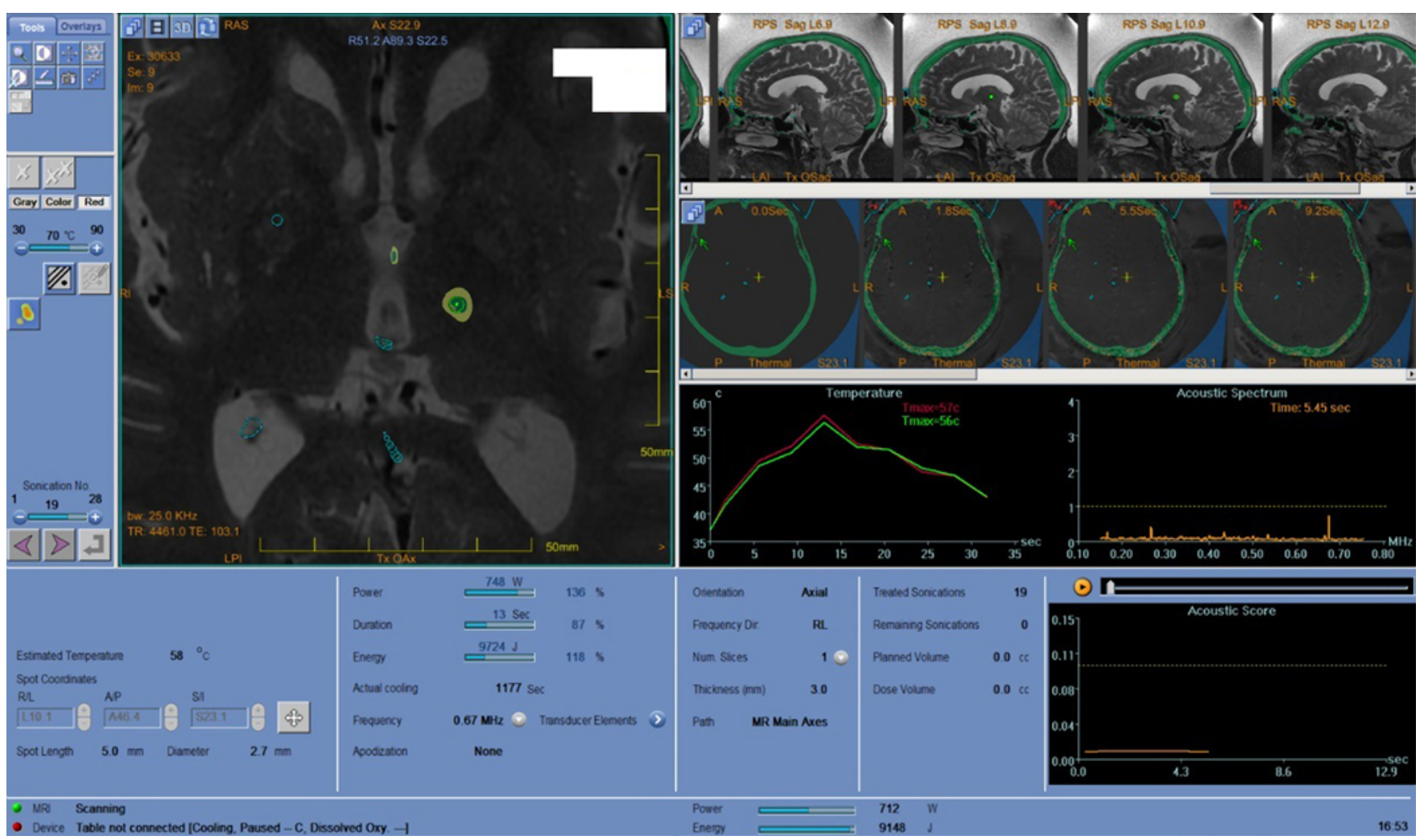

FIG. 2. ExAblate Neuro workstation and treatment plan. 
TABLE 2. Follow-up overview of patients with ET who underwent successful tcMRgFUS

\begin{tabular}{|c|c|c|c|c|c|c|c|c|c|c|}
\hline \multirow{2}{*}{$\begin{array}{c}\text { Case } \\
\text { No. }\end{array}$} & \multicolumn{4}{|c|}{ Hand Score (graphic ability) } & \multicolumn{3}{|c|}{ Global FTM Score } & \multicolumn{3}{|c|}{ QUEST Score } \\
\hline & Baseline & 2 Days & 3 Mos & 6 Mos & Baseline & 3 Mos & 6 Mos & Baseline & 3 Mos & 6 Mos \\
\hline 1 & 3 & 1 & 2 & 6 & 44 & 22 & 29 & 50 & 20.19 & 35 \\
\hline 2 & 5 & 3 & 2 & 0 & 27 & 14 & 17 & 35.83 & 6.73 & 10.83 \\
\hline 3 & 4 & 1 & 1 & 1 & 63 & 17 & 16 & 56.9 & 20 & 20 \\
\hline 4 & 4 & 1 & 1 & 0 & 37 & 10 & 8 & 9.61 & 2.77 & 2.83 \\
\hline 5 & 6 & 3 & 2 & 1 & 37 & 13 & 10 & 29.17 & 10.83 & 9.80 \\
\hline 6 & 6 & 2 & 1 & 1 & 43 & 14 & 12 & 50 & 27 & 27.88 \\
\hline 7 & 13 & 3 & 3 & 2 & 49 & 20 & 17 & 27 & 2.77 & 2.88 \\
\hline 8 & 12 & 3 & 5 & 6 & 54 & 37 & 40 & 26.85 & 40.38 & 49 \\
\hline 9 & 3 & 1 & 1 & In FU & 15 & 9 & In FU & 36.66 & 20.19 & $\ln \mathrm{FU}$ \\
\hline 10 & 8 & 3 & 3 & 3 & 33 & 17 & 18 & 28.84 & 20.19 & 24.04 \\
\hline 11 & 7 & 3 & 3 & In FU & 49 & 26 & In FU & 45.09 & 29.8 & In FU \\
\hline 12 & 6 & 2 & 1 & 2 & 39 & 14 & 14 & 26.85 & 9.61 & 9.8 \\
\hline 13 & 6 & 2 & 2 & 2 & 33 & 12 & 13 & 33.33 & 11.76 & 10.78 \\
\hline Mean & 6.4 & 2.2 & 2.1 & 2.2 & 40.2 & 17.3 & 17.7 & 35.09 & 17.09 & 18.44 \\
\hline
\end{tabular}

achieve temperatures in the range of $50^{\circ}-54^{\circ} \mathrm{C}$ that will result in a transient clinical effect. Once the optimal target was confirmed, and no side effects were reported by the patient, a further increase in the HI-FU beam power was used to achieve higher temperatures $\left(\geq 55^{\circ} \mathrm{C}\right)$ to obtain a permanent lesioning of the targeted volume (Fig. 2) ${ }^{44}$

At the end of each cluster of lesioning sonications, high-resolution T2-weighted sequences were acquired by the dedicated 2-channel head coil to visualize the resulting thalamic lesion. Neither steroid treatment nor osmotic drugs were administered after the treatments.

\section{Results}

For all 13 patients with ET and 4 patients with PD who completed the tcMRgFUS procedure, the thalamic VIM was chosen as the target. In 17 patients the left VIM was ablated, which was contralateral to the dominant hand, in both ET and PD cases. The right VIM was ablated in only 1 patient, which was contralateral from the onset of the tremor, to effectively treat an axial tremor.

\section{Tremor}

All the ET and PD treated patients who completed the

TABLE 3. Follow-up overview of patients with PD who underwent successful tcMRgFUS

\begin{tabular}{ccc}
\hline & \multicolumn{2}{c}{ UPDRS Score $^{*}$} \\
\cline { 2 - 3 } Case No. & Baseline & 3 Mos \\
\hline 20 & 20 & 11 \\
\hline 21 & 38 & 18 \\
\hline 22 & 33 & 15 \\
\hline 23 & 55 & 26 \\
\hline Mean & 36.5 & 17.5 \\
\hline
\end{tabular}

All patients are currently in follow-up at the 6 -month interval.

* Third section of the UPDRS. procedure did show a substantial and immediate improvement in graphical and neurological tests. A subjective improvement of axial and voice tremor was also reported by the patients with ET who suffered from this symptomatology.

At baseline, the FTM global score for all the treated patients with ET showed a mean value of $40.2 \pm 11.8$ (range 15-63) and the second section of the FTM reported a mean hand tremor score of $6.4 \pm 2.97$ (range 3-13). Two days after the treatment, a meaningful $66.4 \%$ reduction of tremor was reported by the second section of the FTM, with a mean value of $2.15 \pm 0.86$ (range $1-3$ ). No improvement was shown in the ipsilateral side of the body to the treated thalamus.

All the patients underwent the 3-month follow-up evaluation, while the 6-month evaluation was performed only in 11 patients with ET. At the 3-month follow-up, a meaningful reduction of $57 \%$ of the global tremor was reported by the FTM, from a mean baseline value of $40.2 \pm 11.8$ to $17.3 \pm 7.31$. In these patients, an improvement of $51 \%$ in their quality of life was reported by the QUEST, from a mean baseline value of $35.09 \pm 12.25$ to a mean value of $17.09 \pm 10.67$ at 3 months. In the 11 patients who also underwent the 6-month follow-up, a meaningful reduction of $58 \%$ of the global tremor was reported by the FTM, from a mean baseline of $41.73 \pm 9.93$ to $17.73 \pm 8.80$, and an improvement of $46 \%$ in their quality of life, from a mean baseline of $34.03 \pm 12.9$ to a mean value of $18.44 \pm 13.76$. An improvement in the graphic ability tests was also documented. All these results will be reevaluated in a longer follow-up (Table 2).

Concerning the 4 treated patients with PD, a significant improvement of $52 \%$ of the tremor was achieved, from a mean tremor score of $36.5 \pm 12.54$ at baseline to a mean tremor score of $17.5 \pm 5.5$ at the 3-month follow-up according to the third section of the UPDRS. All of the patients with PD had not reached the 6-month follow-up at the time of submission of this manuscript (Table 3). 


\section{Adverse Events}

Among the 18 patients with ET enrolled in this study, 5 did not complete the tcMRgFUS procedure. In 4 of them the procedure was aborted because of a sudden and intense remitting headache related to the HI-FU delivery. In the last patient, the procedure was aborted after several sonications because of the failure in reaching a sufficient temperature to perform ultrasonic thalamic ablation, due to the patient's skull thickness and density ratio. ${ }^{12}$ The procedure was voided in a single enrolled patient, who did not undergo any sonication because of a severe blood pressure increase, which led to a transient ischemic attack related to a stress response of the patient to the stereotactic frame placement. The patient was medically treated and monitored in a semi-intensive care unit until the symptoms faded in a few hours.

Among the 13 ET and 4 PD patients enrolled and treated, 2 showed temporary paresthesias to the contralateral hand. One patient showed temporary weakness in grip to the treated hand, which faded in about a week. Four patients showed gait disturbance after the thalamotomy: in 2 of them ataxia completely faded within the time of discharge; in another patient ataxia partially improved within the time of discharge and had completely disappeared at 3 months' follow-up; in the last patient, ataxia was noticed during the entire 6 months of follow-up. Two patients reported a subjective loss of balance; in 1 of these patients it lasted for the entire follow-up period.

In a self-assessment test performed on the 2nd day after the treatment, no patient complained about any moderate or severe disability or any other generic symptoms. Most of the patients reported tiredness, often referring to the hospitalization itself. In only a few patients a slight weakness on the contralateral side of the body was reported.

Regarding the stereotactic frame placement, 3 patients showed temporary headache after the frame removal: 1 patient showed a temporary scalp numbness, which faded in about 24 hours, and 1 patient reported a skin wound due to the placement of the pin of the frame. In a single patient, a minor displacement of the stereotactic frame was reported during the last stages of the treatment, which was corrected by electronic steering only.

During HI-FU delivery, 4 patients complained of dizziness and paroxysmal vertigo. One patient reported a feeling of water flushing around the head even after the frame removal, and a single patient experienced a subjective postural instability leaving the MRI table. No major adverse event was noted.

\section{Neuroradiological Evaluation}

T2-weighted MRI sequences acquired at the end of each treatment showed the resulting thalamotomy as a hyperintense round-shaped lesion with a variable amount of perilesional vasogenic edema. Every treated patient underwent brain MRI 48 hours after the treatment with the reported protocol (Fig. 3). At this time, on T2-weighted pulse sequences, VIM lesions showed the typical imaging findings with 3 typical concentric zones: ${ }^{56}$ a central dark spot (not always clearly appreciable) with a strongly hyperintense peripheral zone demarcated by a hypointense rim and a slightly hyperintense zone of perilesional vasogenic
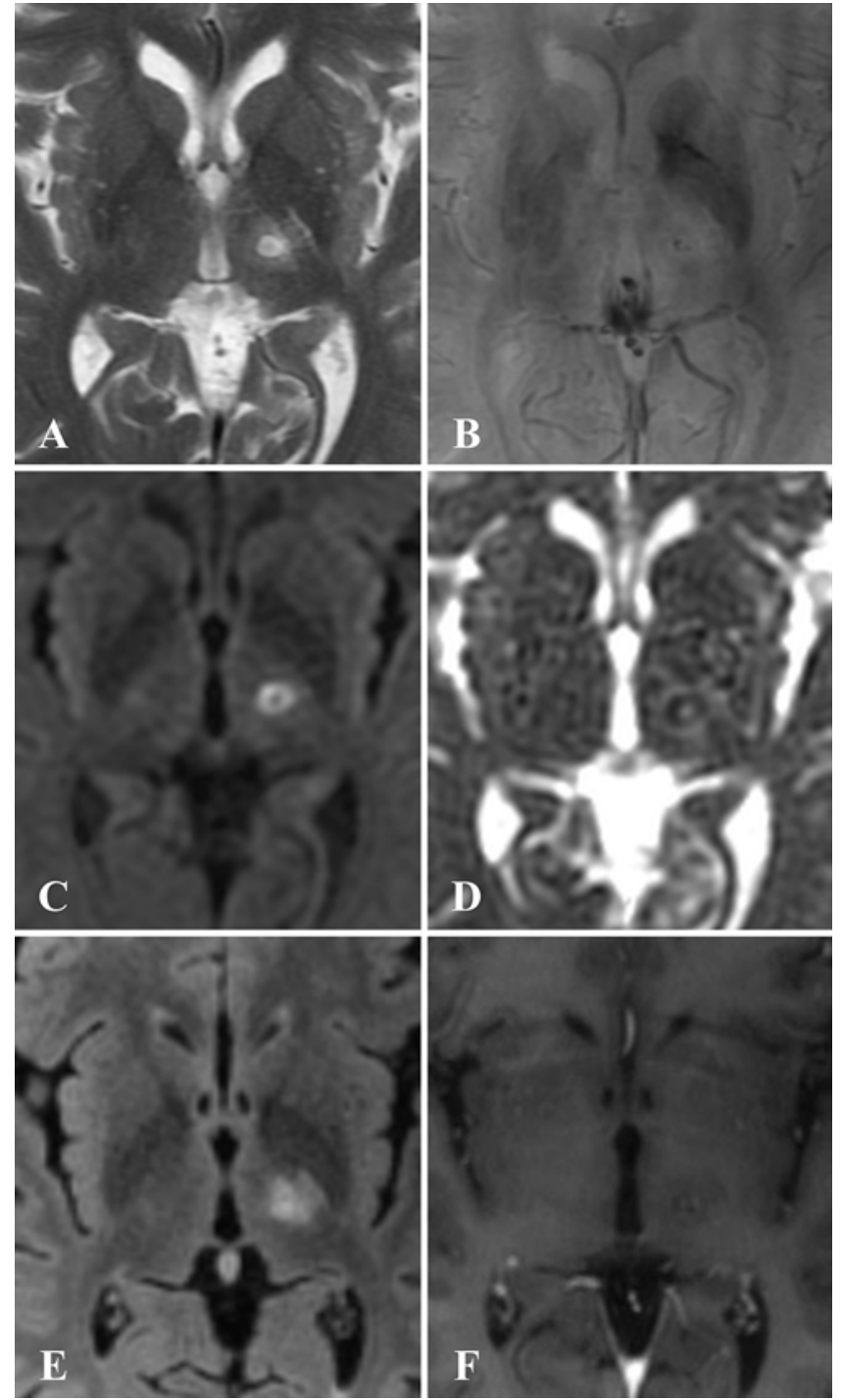

FIG. 3. Posttreatment (48-hour) neuroradiological assessment: axial samples from the MRI protocol used for both screenings and follow-ups using a standard 8-channel phased-array head coil (detail of the basal ganglia region). A: T2-weighted FSE (5-mm thickness) showing the thalamic lesion and the reversible perilesional vasogenic edema spreading laterally among the white matter bundles of the posterior limb of the internal capsule up to the medial edge of the globus pallidus. B: Minimum-intensity projection (3-mm thickness) from the axial 3D SWAN sequence showing intralesional blood products as hypointense spots. $\mathrm{C}$ and D: Echo planar diffusion-weighted imaging (5-mm thickness; C) acquired using $b$ values of 0 and $1000 \mathrm{sec} / \mathrm{mm}^{2}$ and related apparent diffusion coefficient map (D) revealing true restriction of water molecule motion due to coagulation necrosis and protein precipitation. E: Multiplanar reconstruction (3-mm thickness) from the sagittal 3D FLAIR fat-saturated sequence at the same level is less useful for differentiating lesion margins from perilesional tissue compared with T2-weighted FSE sequences. F: Multiplanar reconstruction (3-mm thickness) using an average algorithm from the sagittal 3D FSPGR sequence showing focal areas of T1 shortening due to persistent blood-brain barrier leaks.

edema (Fig. 3A). The lesion itself showed a true restriction of water molecule movements on apparent diffusion coefficient maps (Fig. 3D). Susceptibility-weighted imaging showed blood products within the core of the lesions (Figs. 
3B and 4). At the 48-hour follow-up MRI, all the lesions had almost doubled in size and the amount of perilesional vasogenic edema had increased. On subsequent follow-up images lesion size shrank, until they almost disappeared on T2-weighted pulse sequences after 6-9 months (Fig. 4). In some cases, small spots of blood-brain barrier (BBB) leaks were still appreciable at the 48-hour MRI followup (Fig. 3F), but never on subsequent MRI follow-ups. Susceptibility-weighted imaging revealed the presence of hypointense intralesional blood products (hemosiderin) on all follow-up MRI examinations despite the normalization of other MRI findings on conventional pulse sequences (Fig. 4).

\section{Discussion}

In this clinical series in which $13 \mathrm{ET}$ and 4 hyperkinetic PD patients were evaluated, thalamic VIM ablation was performed by tcMRgFUS. The data obtained did show an amelioration of contralateral tremor, as demonstrated by the results from graphical tests and the FTM. Moreover, a significant quality of life improvement was shown, as assessed by the QUEST questionnaire.

To the best of our knowledge, this is the first series of patients treated with a tcMRgFUS system integrated with a 1.5-T unit. In this method, tcMRgFUS thalamotomy emerges as a safe, effective, and noninvasive technique in treating specific movement disorders, even using the most common and affordable 1.5-T MRI machines. In addition, tcMRgFUS thalamotomy allows a monolateral treatment, compared with traditional deep brain stimulation, but with shorter durations and fewer surgical risks.

The first clinical study of tcMRgFUS feasibility began in 2008 for the treatment of drug-resistant thalamic neuropathic pain. ${ }^{32}$ Further studies about the treatment of behavioral disorders have already been published. ${ }^{38}$

Regarding movement disorder treatment, the study of Elias et al. performed in 2013 demonstrated the effective thalamic VIM ablation through tcMRgFUS in a population of 15 drug-resistant patients with ET. In that series, a significant improvement of tremor and quality of life was obtained after 1 year of follow-up. ${ }^{17}$ The randomized trial that followed that series in 2016 confirmed the effectiveness of tcMRgFUS in 67 patients with ET compared with the sham procedure. ${ }^{18}$ In this trial, an amelioration of hand tremor from 18.1 to 9.6 points was found. In 2013, a second preliminary study about ET treatment through tcMRgFUS confirmed the effectiveness of this technique. ${ }^{41}$ In the same year, positive results were obtained from the tcMRgFUS treatment of 8 patients with PD, with an improvement of $57.1 \%$ at 3 months in the UPDRS evaluation; these results were confirmed in 2014 by a significant UPDRS improvement. ${ }^{42}$

In all the reported series, tcMRgFUS treatments were performed using 3-T MRI machines (Table 4). These units guarantee a greater spatial and contrast resolution but do not guarantee the same safety profile as 1.5 -T MRI machines. ${ }^{33}$ Moreover, compared with 1.5-T magnets, 3-T magnets also suffer from higher susceptibility and dielectric artifacts that could severely influence imaging quality during tcMRgFUS treatments. Our preliminary results
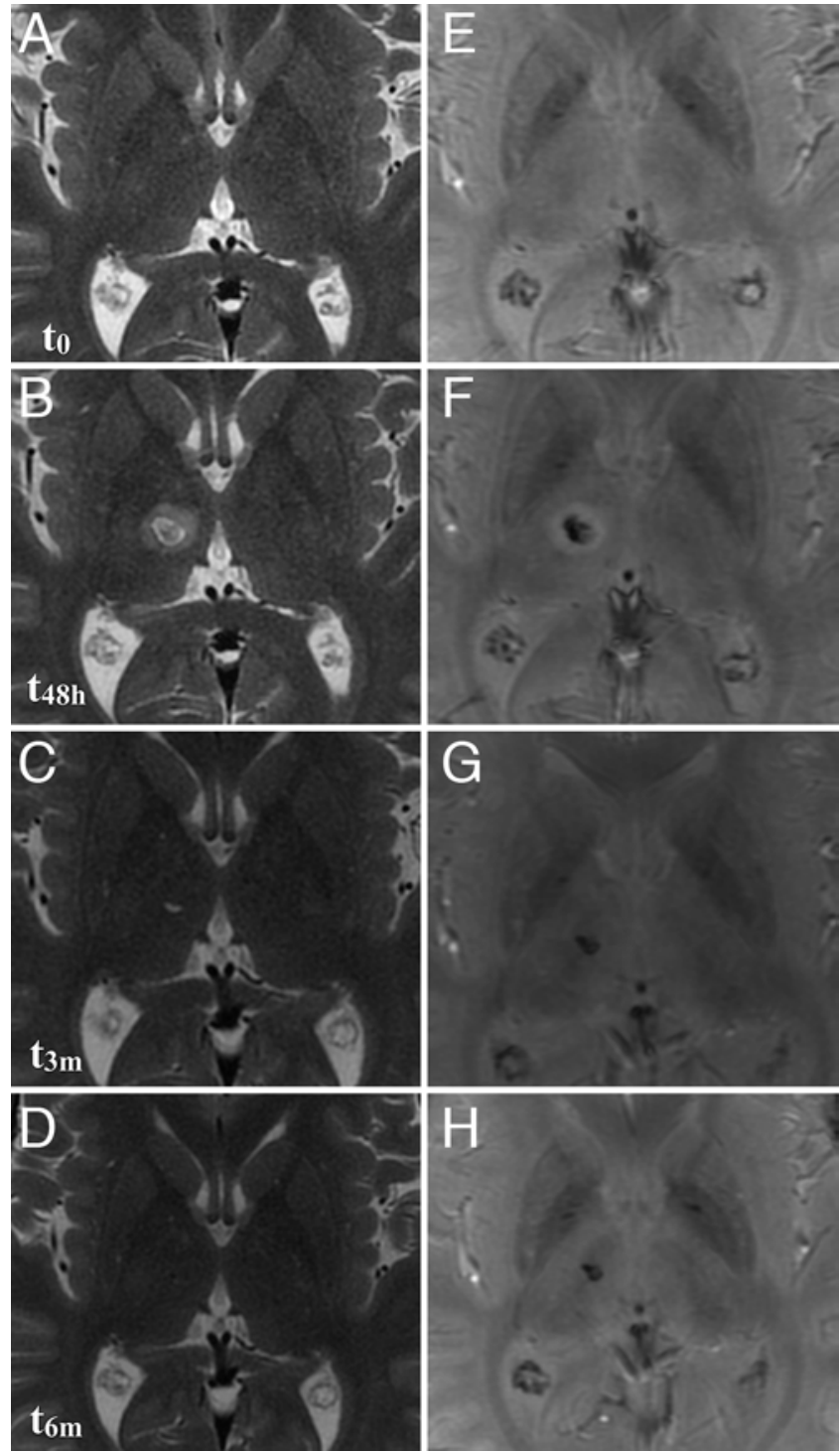

FIG. 4. Axial high-resolution FRFSE (A-D) and axial 3D SWAN (E-H) at different time points: screening MRI $\left(t_{0}, A\right.$ and $\left.E\right), 2$ days ( $t_{48 h}, B$ and $\mathrm{F}), 3$ months ( $\mathrm{t}_{3 \mathrm{~m}}, \mathrm{C}$ and $\left.\mathrm{G}\right)$, and 6 months $\left(\mathrm{t}_{6 \mathrm{~m}}, \mathrm{D}\right.$ and $\left.\mathrm{H}\right)$. The natural evolution of the therapeutic lesion is shown on T2-weighted FSE despite the persistence of blood product deposits even on later follow-up evaluations.

demonstrated the safety and the diagnostic and therapeutic effectiveness of a 1.5-T MRI machine for tcMRgFUS treatments. ${ }^{22,29}$ Regarding effectiveness, no difficulty or error in targeting was encountered and the targeting accuracy was confirmed by the clinical results. Moreover, the feasibility and effectiveness of tcMRgFUS performed with an affordable 1.5-T unit establishes the path to wider use of this emerging technique around the world, because $1.5-\mathrm{T}$ MRI machines are widely installed worldwide and require lower purchase, installation, and maintenance costs.

For a long time, movement disorders and neuropathic pain have been treated with radiofrequency ablation, deep brain stimulation, or stereotactic radiosurgery. Unfortunately, these techniques are burdened by a high rate of ad- 
TABLE 4. Literature case series of patients with motor disorders treated by tcMRgFUS

\begin{tabular}{|c|c|c|c|c|c|}
\hline Authors \& Year & $\begin{array}{l}\text { No. of } \\
\text { Pts }\end{array}$ & Disease & Site of Sonication & $\begin{array}{l}\text { FU } \\
\text { (mos) }\end{array}$ & Complications \\
\hline Elias et al., 2013 & 15 & ET & VIM of the thalamus & 12 & Persistent dysesthesia in dominant index finger $(n=1)$ \\
\hline Lipsman et al., 2013 & 4 & ET & Thalamus & 3 & Paresthesias $(n=1)$, deep vein thrombosis $(n=1)$ \\
\hline Chang et al., 2015 & 8 & ET & VIM of the thalamus & 6 & Vestibular symptoms $(n=5)$, transient balance disturbance $(n=1)$ \\
\hline Magara et al., 2014 & 13 & PD & Pallidothalamic tractotomy & 3 & No procedure- or device-related neurological side effects \\
\hline Chang et al., 2016 & 25 & $\begin{array}{l}15 \mathrm{ET}, 1 \mathrm{PD} \\
9 \mathrm{OCD}\end{array}$ & VIM of the thalamus & NR & NR \\
\hline Elias et al., 2016 & 56 & ET & Thalamus & 12 & Gait disturbance in $36 \%$ \& paresthesias or numbness in 38\% \\
\hline $\begin{array}{l}\text { Schlesinger et al., } \\
\quad 2016\end{array}$ & 7 & PD & VIM of the thalamus & $3-12$ & $\begin{array}{l}\text { HA }(n=3) \text {, dizziness }(n=2) \text {, vertigo }(n=4) \text {, lip paresthesia }(n=1) \text {, } \\
\text { hypogeusia }(n=1) \text {, walking disturbance }(n=2)\end{array}$ \\
\hline Gallay et al., 2016 & 21 & ET & Cerebellothalamic tract & 12 & Gait instability $(n=5)$, walking ability $(n=1)$ \\
\hline Zaaroor et al., 2018 & 30 & $\begin{array}{l}18 \mathrm{ET}, 9 \mathrm{PD} \\
3 \mathrm{ET}-\mathrm{PD}\end{array}$ & VIM of the thalamus & 12 & $\begin{array}{l}\text { HA }(n=11) \text {, vertigo }(n=14) \text {, dizziness }(n=4) \text {, nausea }(n=3) \text {, } \\
\text { burning scalp sensation }(n=3) \text {, vomiting }(n=2) \text {, lip paresthesia } \\
\quad(n=2) \text {, gait ataxia }(n=5) \text {, unsteady feeling }(n=4) \text {, taste distur- } \\
\text { bances }(n=4) \text {, asthenia }(n=4) \text {, hand ataxia }(n=3)\end{array}$ \\
\hline
\end{tabular}

NR = not reported; OCD = obsessive-compulsive disorder; $P$ ts = patients.

All studies used a 3-T MRI machine.

verse events and surgical risks, with possible permanent neurological dysfunctions. ${ }^{10,17}$ Thanks to its noninvasiveness, tcMRgFUS avoids the risk of infection, lowers the risk of bleeding, and reduces adverse effects and damage to the tissues surrounding the target. Also, tcMRgFUS allows clinical outcomes similar to those of radiofrequency ablation thalamotomy or deep brain stimulation, ${ }^{40,53}$ and it also permits one to obtain an immediate and verifiable lesion. ${ }^{11}$ It does not use ionizing radiation and it is a noninvasive technique; moreover, patient feedback allows the physician to optimize the target before a permanent lesion is made, because the clinical effect can be evaluated immediately during each sonication. Furthermore, the use of MRI as a guidance for the HI-FU beam allows a precise real-time location of the target volume, the establishment of precise safety margins, and a real-time temperature control. ${ }^{32}$ Lastly, it may be feasible to more easily consider re-treatment as an option in those cases in which tremor may return.

The profile of adverse events related to tcMRgFUS treatment appears to be similar to the profile of radiofrequency ablation thalamotomy, mainly due to wrong positioning or larger target volume. ${ }^{41}$ However, these risks are limited in tcMRgFUS treatment because it is a noninvasive technique that does not harm skull or brain parenchyma through probe insertion or because of uncontrollable lesion development. Interestingly, a progressive decrease in lesion volume has been shown in the long term after the tcMRgFUS procedure. In contrast, radiofrequency ablation lesions are less spatially controllable, and the Gamma Knife radiosurgical treatment creates lesions that may keep growing over time, with the possible occurrence of progressive neurological deficits. ${ }^{39}$

\section{Future Perspectives in tcMRgFUS}

The feasibility of bilateral tcMRgFUS thalamotomy remains a matter of debate because of the high risk of adverse events in cases of permanent lesioning, in particular ataxia and speech disturbances. ${ }^{4,54}$ Despite this, promising results were obtained by Gallay and colleagues with bilateral cerebellothalamic tractotomy through tcMRgFUS in a series of 18 patients with ET. ${ }^{23}$ Gallay et al.'s study envisages the feasibility of bilateral lesioning without permanent side effects, even if this has not yet been replicated. ${ }^{50}$

Several controlling technologies ${ }^{5}$ and applicable fields are now arising concerning new therapeutic perspectives of tcMRgFUS, such as neurooncological treatment, ${ }^{3,14,43}$ control of BBB permeability, $, 44,45$ controlled drug diffusion ${ }^{34,37}$ and antiblastic therapy across the $\mathrm{BBB}, 2,19,35,43,55$ subcortical drug-resistant epilepsy, obstructive hydrocephalus and drug-resistant psychiatric disorders, ${ }^{46}$ intracranial thrombosis through sonothrombolysis, ${ }^{25}$ and trigeminal neuralgia. ${ }^{47}$

Despite the obtained results, this clinical series suffers from some limitations. Both patients and physicians were aware of the treatment performed in this study; the patient sample is small, and the follow-up duration is ongoing. Moreover, the present study lacks a control group, and therefore it has not been possible to evaluate the effectiveness of tcMRgFUS thalamotomy compared with the other stereotactic procedures that have been performed for a long time. Despite these limitations, every patient showed a significant amelioration of tremor in the treated hand and of the motor function, as shown by results from the clinical tests conducted after treatment. In this way, tcMRgFUS is confirmed as a reliable choice in the treatment of motor disorders, with a high profile of safety and effectiveness, even using a 1.5-T MRI unit.

\section{Acknowledgments}

The installation of the tcMRgFUS equipment used in this study was funded by the Italian Ministry of Education, University and Research, within the project "Programma Operativo Nazionale 
2007-3013" (grant no. PONa3_00011) under the direction of Prof. Carlo Catalano, the project leader.

\section{References}

1. Ahmed H, Field W, Hayes MT, Lopez WOC, McDannold N, Mukundan S Jr, et al: Evolution of movement disorders surgery leading to contemporary focused ultrasound therapy for tremor. Magn Reson Imaging Clin N Am 23:515-522, 2015

2. Airan RD, Foss CA, Ellens NPK, Wang Y, Mease RC, Farahani K, et al: MR-guided delivery of hydrophilic molecular imaging agents across the blood-brain barrier through focused ultrasound. Mol Imaging Biol 19:24-30, 2017

3. Alongi F, Russo G, Spinelli A, Borasi G, Scorsetti M, Gilardi $\mathrm{MC}$, et al: Can magnetic resonance image-guided focused ultrasound surgery replace local oncology treatments? A review. Tumori 97:259-264, 2011

4. Alshaikh J, Fishman PS: Revisiting bilateral thalamotomy for tremor. Clin Neurol Neurosurg 158:103-107, 2017

5. Arvanitis CD, Livingstone MS, McDannold N: Combined ultrasound and MR imaging to guide focused ultrasound therapies in the brain. Phys Med Biol 58:4749-4761, 2013

6. Aubry JF, Tanter M, Pernot M, Thomas JL, Fink M: Experimental demonstration of noninvasive transskull adaptive focusing based on prior computed tomography scans. J Acoust Soc Am 113:84-93, 2003

7. Bauer R, Martin E, Haegele-Link S, Kaegi G, von Specht M, Werner B: Noninvasive functional neurosurgery using transcranial MR imaging-guided focused ultrasound. Parkinsonism Relat Disord 20 (Suppl 1):S197-S199, 2014

8. Berardelli A, Wenning GK, Antonini A, Berg D, Bloem BR, Bonifati V, et al: EFNS/MDS-ES/ENS recommendations for the diagnosis of Parkinson's disease. Eur J Neurol 20:16-34, 2013 (Erratum in Eur J Neurol 20:406, 2013)

9. Burgess A, Hynynen K: Drug delivery across the blood-brain barrier using focused ultrasound. Expert Opin Drug Deliv 11:711-721, 2014

10. Campbell AM, Glover J, Chiang VLS, Gerrard J, Yu JB: Gamma knife stereotactic radiosurgical thalamotomy for intractable tremor: a systematic review of the literature. Radiother Oncol 114:296-301, 2015

11. Chang WS, Jung HH, Kweon EJ, Zadicario E, Rachmilevitch I, Chang JW: Unilateral magnetic resonance guided focused ultrasound thalamotomy for essential tremor: practices and clinicoradiological outcomes. J Neurol Neurosurg Psychiatry 86:257-264, 2015

12. Chang WS, Jung HH, Zadicario E, Rachmilevitch I, Tlusty T, Vitek S, et al: Factors associated with successful magnetic resonance-guided focused ultrasound treatment: efficiency of acoustic energy delivery through the skull. J Neurosurg 124:411-416, 2016

13. Clement GT, Hynynen K: A non-invasive method for focusing ultrasound through the human skull. Phys Med Biol 47:1219-1236, 2002

14. Coluccia D, Fandino J, Schwyzer L, O'Gorman R, Remonda $\mathrm{L}$, Anon J, et al: First noninvasive thermal ablation of a brain tumor with MR-guided focused ultrasound. J Ther Ultrasound 2:17, 2014

15. Dababou S, Marrocchio C, Rosenberg J, Bitton R, Pauly KB, Napoli A, et al: A meta-analysis of palliative treatment of pancreatic cancer with high intensity focused ultrasound. J Ther Ultrasound 5:9, 2017

16. Dobrakowski PP, Machowska-Majchrzak AK, Labuz-Roszak B, Majchrzak KG, Kluczewska E, Pierzchała KB: MR-guided focused ultrasound: a new generation treatment of Parkinson's disease, essential tremor and neuropathic pain. Interv Neuroradiol 20:275-282, 2014

17. Elias WJ, Huss D, Voss T, Loomba J, Khaled M, Zadicario E, et al: A pilot study of focused ultrasound thalamotomy for essential tremor. N Engl J Med 369:640-648, 2013
18. Elias WJ, Lipsman N, Ondo WG, Ghanouni P, Kim YG, Lee $\mathrm{W}$, et al: A randomized trial of focused ultrasound thalamotomy for essential tremor. N Engl J Med 375:730-739, 2016

19. Etame AB, Diaz RJ, Smith CA, Mainprize TG, Hynynen K, Rutka JT: Focused ultrasound disruption of the blood-brain barrier: a new frontier for therapeutic delivery in molecular neurooncology. Neurosurg Focus 32(1):E3, 2012

20. Ferreira JJ, Katzenschlager R, Bloem BR, Bonuccelli U, Burn D, Deuschl G, et al: Summary of the recommendations of the EFNS/MDS-ES review on therapeutic management of Parkinson's disease. Eur J Neurol 20:5-15, 2013

21. Fry WJ, Fry FJ, Barnard JW, Krumins RF, Brennan JF: Ultrasonic lesions in mammalian central nervous system. Science 122:1091, 1955

22. Gagliardo C, Geraci L, Napoli A, Giugno A, Cortegiani A, Canzio D, et al: [Non-invasive trans-cranial magnetic resonance imaging-guided focused ultrasounds surgery to treat neurologic disorders.] Recenti Prog Med 107:242-245, 2016 (Ital)

23. Gallay MN, Moser D, Rossi F, Pourtehrani P, Magara AE, Kowalski M, et al: Incisionless transcranial MR-guided focused ultrasound in essential tremor: cerebellothalamic tractotomy. J Ther Ultrasound 4:5, 2016

24. Geraci L, Napoli A, Catalano C, Midiri M, Gagliardo C: Magnetic resonance imaging-guided focused ultrasound surgery for the treatment of symptomatic uterine fibroids. Case Rep Radiol 2017:2520989, 2017

25. Hölscher T, Raman R, Fisher DJ, Ahadi G, Zadicario E, Voie A: Effects of varying duty cycle and pulse width on highintensity focused ultrasound (HIFU)-induced transcranial thrombolysis. J Ther Ultrasound 1:18, 2013

26. Horstink M, Tolosa E, Bonuccelli U, Deuschl G, Friedman A, Kanovsky P, et al: Review of the therapeutic management of Parkinson's disease. Report of a joint task force of the European Federation of Neurological Societies (EFNS) and the Movement Disorder Society-European Section (MDS-ES). Part II: late (complicated) Parkinson's disease. Eur J Neurol 13:1186-1202, 2006

27. Hurwitz MD, Ghanouni P, Kanaev SV, Iozeffi D, Gianfelice D, Fennessy FM, et al: Magnetic resonance-guided focused ultrasound for patients with painful bone metastases: phase III trial results. J Natl Cancer Inst 106:dju082, 2014

28. Hynynen K, Clement GT, McDannold N, Vykhodtseva N, King R, White PJ, et al: 500-element ultrasound phased array system for noninvasive focal surgery of the brain: a preliminary rabbit study with ex vivo human skulls. Magn Reson Med 52:100-107, 2004

29. Iacopino DG, Giugno A, Maugeri R, Gagliardo C, Franzini A, Catalano C, et al: Is there still a role for lesioning in functional neurosurgery? Preliminary Italian (and world-first) experience with a trans-cranial MRI-guided focused ultrasound surgery system operating at 1.5 Tesla. J Neurosurg Sci 61:681-683, 2017

30. Ishihara Y, Calderon A, Watanabe H, Okamoto K, Suzuki Y, Kuroda K, et al: A precise and fast temperature mapping using water proton chemical shift. Magn Reson Med 34:814823,1995

31. Jagannathan J, Sanghvi NT, Crum LA, Yen CP, Medel R, Dumont AS, et al: High-intensity focused ultrasound surgery of the brain: part 1-a historical perspective with modern applications. Neurosurgery 64:201-211, 2009

32. Jeanmonod D, Werner B, Morel A, Michels L, Zadicario E, Schiff G, et al: Transcranial magnetic resonance imagingguided focused ultrasound: noninvasive central lateral thalamotomy for chronic neuropathic pain. Neurosurg Focus 32(1):E1, 2012

33. Jerrolds J, Keene SM: MRI safety at 3T versus 1.5T. Internet J Radiol 11:1-8, 2010

34. Jolesz FA: Science to practice: opening the blood-brain bar- 
rier with focused ultrasound-a potential treatment for Alzheimer disease? Radiology 273:631-633, 2014

35. Jolesz FA, Hynynen K, McDannold N, Tempany C: MR imaging-controlled focused ultrasound ablation: a noninvasive image-guided surgery. Magn Reson Imaging Clin N Am 13:545-560, 2005

36. Jolesz FA, McDannold NJ: Magnetic resonance-guided focused ultrasound: a new technology for clinical neurosciences. Neurol Clin 32:253-269, 2014

37. Jordão JF, Thévenot E, Markham-Coultes K, Scarcelli T, Weng YQ, Xhima K, et al: Amyloid- $\beta$ plaque reduction, endogenous antibody delivery and glial activation by braintargeted, transcranial focused ultrasound. Exp Neurol 248:16-29, 2013

38. Jung HH, Chang WS, Rachmilevitch I, Tlusty T, Zadicario E, Chang JW: Different magnetic resonance imaging patterns after transcranial magnetic resonance-guided focused ultrasound of the ventral intermediate nucleus of the thalamus and anterior limb of the internal capsule in patients with essential tremor or obsessive-compulsive disorder. J Neurosurg 122:162-168, 2015

39. Kondziolka D, Ong JG, Lee JYK, Moore RY, Flickinger JC, Lunsford LD: Gamma Knife thalamotomy for essential tremor. J Neurosurg 108:111-117, 2008

40. Kumar R, Lozano AM, Sime E, Lang AE: Long-term followup of thalamic deep brain stimulation for essential and parkinsonian tremor. Neurology 61:1601-1604, 2003

41. Lipsman N, Schwartz ML, Huang Y, Lee L, Sankar T, Chapman M, et al: MR-guided focused ultrasound thalamotomy for essential tremor: a proof-of-concept study. Lancet Neurol 12:462-468, 2013

42. Magara A, Bühler R, Moser D, Kowalski M, Pourtehrani P, Jeanmonod D: First experience with MR-guided focused ultrasound in the treatment of Parkinson's disease. J Ther Ultrasound 2:11, 2014

43. McDannold N, Clement GT, Black P, Jolesz F, Hynynen K: Transcranial magnetic resonance imaging- guided focused ultrasound surgery of brain tumors: initial findings in 3 patients. Neurosurgery 66:323-332, 2010

44. McDannold N, Vykhodtseva N, Jolesz FA, Hynynen K: MRI investigation of the threshold for thermally induced bloodbrain barrier disruption and brain tissue damage in the rabbit brain. Magn Reson Med 51:913-923, 2004

45. McDannold N, Vykhodtseva N, Raymond S, Jolesz FA, Hynynen K: MRI-guided targeted blood-brain barrier disruption with focused ultrasound: histological findings in rabbits. Ultrasound Med Biol 31:1527-1537, 2005

46. Monteith S, Sheehan J, Medel R, Wintermark M, Eames M, Snell J, et al: Potential intracranial applications of magnetic resonance-guided focused ultrasound surgery. J Neurosurg 118:215-221, 2013

47. Monteith SJ, Medel R, Kassell NF, Wintermark M, Eames $\mathrm{M}$, Snell J, et al: Transcranial magnetic resonance-guided focused ultrasound surgery for trigeminal neuralgia: a cadaveric and laboratory feasibility study. J Neurosurg 118:319328,2013

48. Napoli A, Anzidei M, Ciolina F, Marotta E, Cavallo Marincola B, Brachetti G, et al: MR-guided high-intensity focused ultrasound: current status of an emerging technology. Cardiovasc Intervent Radiol 36:1190-1203, 2013

49. Napoli A, Mastantuono M, Cavallo Marincola B, Anzidei
M, Zaccagna F, Moreschini O, et al: Osteoid osteoma: MRguided focused ultrasound for entirely noninvasive treatment. Radiology 267:514-521, 2013

50. Rohani M, Fasano A: Focused ultrasound for essential tremor: review of the evidence and discussion of current hurdles. Tremor Other Hyperkinet Mov (N Y) 7:462, 2017

51. Rossi PJ, Gunduz A, Judy J, Wilson L, Machado A, Giordano JJ, et al: Proceedings of the Third Annual Deep Brain Stimulation Think Tank: a review of emerging issues and technologies. Front Neurosci 10:119, 2016

52. Schlesinger D, Benedict S, Diederich C, Gedroyc W, Klibanov A, Larner J: MR-guided focused ultrasound surgery, present and future. Med Phys 40:080901, 2013

53. Schuurman PR, Bosch DA, Bossuyt PMM, Bonsel GJ, van Someren EJW, de Bie RMA, et al: A comparison of continuous thalamic stimulation and thalamotomy for suppression of severe tremor. N Engl J Med 342:461-468, 2000

54. Tasker RR: Deep brain stimulation is preferable to thalamotomy for tremor suppression. Surg Neurol 49:145-154, 1998

55. Treat LH, McDannold N, Vykhodtseva N, Zhang Y, Tam K, Hynynen K: Targeted delivery of doxorubicin to the rat brain at therapeutic levels using MRI-guided focused ultrasound. Int J Cancer 121:901-907, 2007

56. Wintermark M, Druzgal J, Huss DS, Khaled MA, Monteith $\mathrm{S}$, Raghavan $\mathrm{P}$, et al: Imaging findings in MR imaging-guided focused ultrasound treatment for patients with essential tremor. AJNR Am J Neuroradiol 35:891-896, 2014

57. Zaaroor M, Sinai A, Goldsher D, Eran A, Nassar M, Schlesinger I: Magnetic resonance-guided focused ultrasound thalamotomy for tremor: a report of 30 Parkinson's disease and essential tremor cases. J Neurosurg 128:202210, 2018

\section{Disclosures}

The authors report no conflict of interest concerning the materials or methods used in this study or the findings specified in this paper.

\section{Author Contributions}

Conception and design: Maugeri, Iacopino, Gagliardo, Giammalva, Catalano, Fierro, Midiri, Lagalla. Acquisition of data: Iacopino, Gagliardo, Giugno, Giammalva, Valentino, Cosentino, D’Amelio, Fierro, Midiri, Lagalla. Analysis and interpretation of data: Maugeri, Iacopino, Gagliardo, Giammalva, Napoli, Valentino, Cosentino, D'Amelio, Catalano, Fierro, Midiri. Drafting the article: Maugeri, Gagliardo, Giammalva. Critically revising the article: Maugeri, Iacopino, Gagliardo, Napoli, Graziano, Valentino, Cosentino, D’Amelio, Bartolotta, Catalano, Lagalla. Reviewed submitted version of manuscript: Maugeri, Iacopino, Gagliardo, Napoli, Graziano, Valentino, Cosentino, D’Amelio, Bartolotta, Catalano. Approved the final version of the manuscript on behalf of all authors: Maugeri. Statistical analysis: Giammalva. Administrative/technical/material support: Iacopino, Fierro, Midiri, Lagalla. Study supervision: Maugeri, Iacopino, Midiri, Lagalla.

\section{Correspondence}

Rosario Maugeri: University of Palermo, Italy. rosario. maugeri1977@gmail.com. 